term follow-up of patients treated with 17 pacing and seyuential pacing with special reference to VA retrograde conduction. PACF 1988;11:1929-34 13 Fitzpatrick A, Theodorakis G, Vardas P, Kenny RA, Travill C.M, Ingram A, et al. The incidence of malignant vasovagal ssndrome in patients with recurrent syncope. Fur Heart f 1991;12:389-94

14 Pacemakers-practice and paradex. Lancet 1991:338:1178-9.

\title{
The role of non-steroidal anti-inflammatory drugs in acute liver injury 市
}

\author{
Luis A García Rodriguez, Susanne Pérez Gutthann, Alexander M Walker, Leah Lueck
}

\begin{abstract}
Objective-To investigate the association between use of non-steroidal anti-inflammatory drugs and serious, acute non-infectious liver injury.

Design-Retrospective cohort study, cross over design.
\end{abstract}

Setting-Health records from provincial database in Saskatchewan, Canada, 1982-6.

Subjects-228392 adults who contributed 645456 person years. All were either using or had used nonsteroidal anti-inflammatory drugs.

Main outcome measures-Number and type of prescriptions for non-steroidal anti-inflammatory drugs. Admission to hospital for newly diagnosed acute liver injury.

Results-There were 34 admissions to hospital; 16 among subjects currently using non-steroidal antiinflammatory drugs and 18 among subjects who were not. The incidence rate among current users was 9 per 100000 person years $(95 \%$ confidence interval 6 to 15 per 100000 person years). Subjects currently using non-steroidal anti-inflammatory drugs had twice the risk of newly diagnosed liver injury as those not currently taking these drugs (rate ratio 2.3 ; $95 \%$ confidence interval 1.1 to 4.9 ) and an excess risk of 5 per 100000 person years. The age and sex adjusted risk ratio was $1.7(0.8$ to 3.7$)$. The strength of the association increased when only cases with no concomitant use of other hepatotoxic drugs were considered $(4.0 ; 0.9$ to 19.0$)$. The rate ratio for people having received one to nine prescriptions was constant. There was no increased risk with long duration of treatment $(1 \cdot 0 ; 0 \cdot 3$ to $3 \cdot 5)$.

Conclusions-There is a small excess risk of serious, acute non-infectious liver injury associated with the use of non-steroidal anti-inflammatory drugs.

Unit, Ciba-Geigy AG

Basel, Switzerland

Luis A Garcia Rodriguez, assistant professor

Susanne Pérez Gutthann, researcher

\section{Department of}

Epidemiology, Harvard

University School of Public

Health, Boston, USA

Alexander M Walker,

professor

GDS and Associates

Systems Ltd, Regina,

Canada

Leah Lueck, system analyst

Correspondence to:

Dr Garcia Rodriguez,

Boston Collaborative Drug

Surveillance Program,

Boston University Medical

Center, Lexington,

Massachusetts 02173, USA

BMF 1992;305:865-8
To provide additional information on the role of nonsteroidal anti-inflammatory drugs in acute liver injury we carried out a retrospective cohort study to evaluate the clinical features and incidence of acute noninfectious liver injury serious enough to require admission to hospital (with no other documented cause) in users of non-steroidal anti-inflammatory drugs by using the computerised databases of Saskatchewan Health in Canada. We also estimated the background $D$ incidence of admission for acute liver injury in the same population when they were not taking nonsteroidal anti-inflammatory drugs.

\section{Subjects and methods}

Over $95 \%$ of the 1.1 million residents of the province of Saskatchewan are entitled to receive medical benefits through the department of health. ${ }^{4}$ As a byproduct of providing these health services, the $\overrightarrow{\mathscr{\theta}}$ Saskatchewan health plan has accumulated a large ? amount of medical care information on computerised databases over the past 20 years. This includes prescription data, outpatient and hospital diagnostic information, cancer and vital statistics, and records of special medical and supportive services. Most of these databases may be linked by a unique patient identifier. As a result a complete chronological profile of prescriptions, outpatient visits, and admissions to hospital is available for all patients included in the health plan. The population of the province is stable with low rates of immigration and emigration.

This study was part of a research project designed to look at the association between concurrent use of nonsteroidal anti-inflammatory drugs and several serious outcomes among the population from January 1982 to December 1986. Any member of the health plan filling a prescription for one of five drugs (diclofenac, $)$ indomethacin, naproxen, sulindac, and piroxicam) $N$ entered the study population and was followed up until $\rightarrow$ admission to hospital for hepatitis, death, departure from the health plan, or end of the study period.

The methods for classifying person time have been $\mathrm{N}$ presented in detail elsewhere. ${ }^{5}$ Briefly, subjects were categorised into current use of non-steroidal antiinflammatory drugs, which included the 60 days after a prescription, or no current use, which included all the $\mathscr{D}$ remaining eligible person time of observation. Current use was further classified according to the most recent 0 drug dispensed. Every prescription filled after the $\mathbb{\mathbb { D }}$ patient became a study member was identified. During the study 12 non-steroidal anti-inflammatory drugs were available only through prescription, and aspirin was available over the counter. Subjects could pass 8 back and forth between the categories of use, determined by the dates on which the drugs were dispensed.

Periods of current use of non-steroidal anti-? inflammatory drugs were categorised according to the total preceding number of consecutive prescriptionsthat is, prescriptions that followed within 90 days of 
one another. Duration of use for patients exposed to the drugs was calculated as the total number of consecutive prescriptions filled before admission to hospital, and the daily dose was estimated according to the strength and quantity prescribed and the time interval between two consecutive prescriptions or index date, or both.

We identified the first admission to hospital for any of the following primary discharge diagnoses (International Classification of Diseases ninth revision (ICD-9) codes) from the hospital services plan database: acute and subacute necrosis of the liver (570), unspecified hepatitis (573.3), and jaundice (782.4). For each person admitted an automated patient profile was produced. The profile included details of all outpatient visits, admissions, and selective use of drugs as an outpatient (with no data on use of non-steroidal

TABLE I-Distribution of age, sex, and use of non-steroidal anti-inflammatory drugs in study population

\begin{tabular}{|c|c|c|c|c|c|c|c|}
\hline & \multirow{2}{*}{$\begin{array}{l}\text { Total } \\
\text { (No) }\end{array}$} & \multirow{2}{*}{$\begin{array}{l}\text { Men } \\
(\%)\end{array}$} & \multirow{2}{*}{$\begin{array}{l}\text { Women } \\
(\%)\end{array}$} & \multicolumn{2}{|c|}{ Age (years) } & \multirow{2}{*}{$\begin{array}{l}\text { No of } \\
\text { prescrip- } \\
\text { tions }\end{array}$} & \multirow{2}{*}{$\begin{array}{c}\text { Person } \\
\text { years }\end{array}$} \\
\hline & & & & $0-64(\%)$ & $\geqslant 65(\%)$ & & \\
\hline Study population & $228392^{\star}$ & 46 & 54 & 75 & 25 & 1523559 & $177550+$ \\
\hline \multicolumn{8}{|c|}{ Users of non-steroidal anti-inflammatory drugs } \\
\hline Naproxen & 90385 & 44 & 56 & 78 & 22 & 257787 & 31281 \\
\hline Indomethacin & 81848 & 50 & 50 & 72 & 28 & 289802 & 32443 \\
\hline Piroxicam & 80901 & 42 & 58 & 66 & 34 & 358140 & 40073 \\
\hline Diclofenac & 38383 & 44 & 56 & 71 & 29 & 101061 & 11434 \\
\hline Sulindac & 32468 & 43 & 57 & 68 & 32 & 106670 & 12465 \\
\hline Ibuprofen & 34976 & 41 & 59 & 72 & 28 & 101500 & 11435 \\
\hline Aspirin & 28879 & 38 & 62 & 52 & 48 & 159528 & 13646 \\
\hline Diflunisal & 18874 & 44 & 56 & 75 & 25 & 43735 & 4677 \\
\hline Ketoprofen & 15856 & 36 & 64 & 61 & 39 & 50492 & 5383 \\
\hline Phenylbutazone & 8185 & 50 & 50 & 67 & 33 & 15760 & 1777 \\
\hline Mefenamic acid & 6383 & 12 & 88 & 90 & 10 & 12726 & 1570 \\
\hline Fenoprofen & 5357 & 41 & 59 & 67 & 33 & 18612 & 1983 \\
\hline Tolmetin & 2436 & 38 & 62 & 71 & 29 & 7746 & 776 \\
\hline
\end{tabular}

*People receiving at least one prescription. As one person may have been prescribed different non-steroidal antiinflammatory drugs during 1982-6 the sum of individual users is greater than total study population.

†Prescriptions of several different non-steroidal anti-inflammatory drugs filled on same day accounted for 8607 person years. Person time contributed by study population when not taking non-steroidal anti-inflammatory drugs totalled 467906 person years.

TABLE II-Summary of cases of acute liver injury not attributable to liver disease or causes for liver disease, according to use of non-steroidal anti-inflammatory drugs

\begin{tabular}{|c|c|c|c|c|c|c|c|}
\hline $\begin{array}{l}\text { Non-steroidal } \\
\text { anti-inflammatory } \\
\text { drugs }\end{array}$ & $\mathrm{Rx}^{\star}$ & $\begin{array}{l}\text { Daily } \\
\text { dose } \\
(\mathrm{mg}) \dagger\end{array}$ & $\begin{array}{c}\text { Year of } \\
\text { admission }\end{array}$ & Sex & Age & $\begin{array}{c}\text { Use of other } \\
\text { hepatotoxic drug } \\
\text { before admission }{ }^{12}\end{array}$ & $\begin{array}{l}\text { Type of } \\
\text { injury }\end{array}$ \\
\hline \multicolumn{8}{|c|}{ Subjects currently taking non-steroidal anti-inflammatory drugs $(n=16)$} \\
\hline Sulindac/aspirin $\ddagger$ & $19 / 0$ & $400 / 0$ & 1982 & $\mathrm{~F}$ & 78 & No & Cholestatic \\
\hline Indomethacin & 1 & 75 & 1983 & $M$ & 22 & Nó & Hepatocellular \\
\hline Sulindac & 1 & 300 & 1984 & $\mathrm{~F}$ & 93 & No & Cholestatic \\
\hline Sulindac & 3 & 300 & 1984 & $\mathrm{~F}$ & 78 & No & Cholestatic \\
\hline Naproxen & 9 & 500 & 1984 & $\mathrm{~F}$ & 78 & No & Cholestaticf \\
\hline Diclofenac/piroxicam & $3 / 1$ & $100 / 20$ & 1986 & $\mathrm{~F}$ & 63 & No & Data missing \\
\hline Indomethacin/sulindac & $1 / 2$ & $100 / 400$ & 1982 & $M$ & 76 & Yes & Hepatocellulars \\
\hline Naproxen & 2 & 500 & 1982 & $\mathrm{~F}$ & 33 & Yes & Hepatocellular \\
\hline Piroxicam & 2 & 20 & 1982 & $\mathrm{~F}$ & 70 & Yes & Cholestatic \\
\hline Aspirin/indomethacin & $19 / 1$ & $650 / 75$ & 1984 & $M$ & 80 & Yes & Cholestatic \\
\hline Piroxicam & 19 & 20 & 1985 & $\mathrm{~F}$ & 65 & Yes & Cholestatic \\
\hline Aspirin/sulindac & $5 / 1$ & $1300 / 400$ & 1985 & $M$ & 68 & Yes & Cholestatic \\
\hline Piroxicam & 1 & 20 & 1985 & $\mathrm{~F}$ & 31 & Yes & Mixed \\
\hline Ibuprofen & 1 & 1200 & 1986 & $M$ & 93 & Yes & Cholestatic \\
\hline Indomethacin & 1 & 75 & 1986 & $\mathrm{~F}$ & 58 & Yes & Hepatocellular \\
\hline Naproxen & 5 & 1125 & 1986 & M & 77 & Yes & Cholestatic \\
\hline \multicolumn{8}{|c|}{ Subjects not currently taking non-steroidal anti-inflammatory drugs $(n=18)$} \\
\hline & & & 1983 & $\mathrm{~F}$ & 46 & No & Cholestatic \\
\hline & & & 1985 & $\mathrm{~F}$ & 57 & No & Hepatocellular \\
\hline & & & 1985 & $\mathrm{~F}$ & 42 & No & Hepatocellular \\
\hline & & & 1986 & $M$ & 80 & No & Hepatocellular \\
\hline & & & 1983 & $\mathrm{~F}$ & 21 & Yes & Hepatocellular \\
\hline & & & 1984 & M & 88 & Yes & Cholestatic \\
\hline & & & 1984 & $M$ & 28 & Yes & Hepatocellular \\
\hline & & & 1984 & $\mathrm{~F}$ & 87 & Yes & Cholestatic \\
\hline & & & 1984 & $\mathrm{~F}$ & 37 & Yes & Hepatocellular \\
\hline & & & 1985 & $M$ & 62 & Yes & Mixed \\
\hline & & & 1985 & $M$ & 54 & Yes & Cholestatic \\
\hline & & & 1985 & $\mathrm{~F}$ & 86 & Yes & Hepatocellular \\
\hline & & & 1985 & $\mathrm{~F}$ & 65 & Yes & Hepatocellular \\
\hline & & & 1985 & $\mathrm{~F}$ & 39 & Yes & Hepatocellular \\
\hline & & & 1986 & $M$ & 73 & Yes & Cholestatic \\
\hline & & & 1986 & $\mathrm{~F}$ & 90 & Yes & Cholestatic \\
\hline & & & 1986 & $\mathrm{~F}$ & 71 & Yes & Mixed \\
\hline & & & 1986 & $\mathrm{~F}$ & 55 & Yes & Mixed \\
\hline
\end{tabular}

*Number of consecutive prescriptions before hospitalisation.

†Estimated according to strength, quantity, and time interval between consecutive prescriptions.

$\ddagger$ Aspirin bought over counter.

Patient died during admission. anti-inflammatory drugs) from 1982 until one year after the admission of interest. For these admissions trained nurses visited the hospitals to collect the data, including a full transcript of the discharge summary, drug use before admission, laboratory test results, results from other diagnostic procedures, and previous admissions. Any data that would identify a patient or physician were suppressed.

Patients with no documented liver disease or with concomitant causal mechanisms for their liver disease (alcoholism, malignant neoplasm, cholelithiasis, viral hepatitis (diagnosis based on serological test results), chronic liver disease, cirrhosis, congestive heart failure, hepatitis after blood transfusion, other well-defined pathology $y^{6-10}$ ) were excluded from the final analysis. Acute liver injury was defined as an increase of twice or more the upper limit of the normal range in alanine aminotransferase or a combined increase in aspartate aminotransferase, alkaline phosphatase, and total bilirubin, provided one of them was twice the upper limit of normal. ${ }^{11}$ Acute liver injury was designated hepatocellular when there was an increase of more than twice the upper limit of the normal range in alanine aminotransferase or when the ratio (R) of serum activity of alanine aminotransferase to serum activity of alkaline phosphatase was $\geqslant 5$. Acute liver injury was designated cholestatic when there was an increase of over twice the upper limit of the normal range in alkaline phosphatase alone or $R \leqslant 2$. Liver injury was designated mixed when both alanine aminotransferase and alkaline phosphatase were increased and $2<\mathrm{R}<5$.

To take into account the effect of other potential hepatotoxic drugs, ${ }^{12}$ the final cases were divided into two subgroups according to use of hepatotoxic drugs other than non-steroidal anti-inflammatory drugs before admission to hospital.

Incidence rates were calculated by dividing the number of cases of acute liver injury in each category of use by the corresponding number of person years. Exact $95 \%$ confidence intervals were derived on the basis of an assumed Poisson distribution of case counts within categories of use. ${ }^{13}$ The EXACT program was used to compute crude and summary rate ratios across categories with sparse information. ${ }^{14}$

\section{Results}

The total study population comprised 228392 people who contributed 645456 person years of observation and filled over 1.5 million prescriptions for the 13 non-steroidal anti-inflammatory drugs (including aspirin) included in the study. Table I presents the age and sex distribution for the study population and the total number of prescriptions and the person time contribution. There were 177550 person years when subjects were taking non-steroidal anti-inflammatory drugs (current use) and 467906 person years when they were not (no current use)

One hundred and twenty seven first admissions to hospital were initially identified on the database. Ninety three patients were excluded on the basis of their computer and hospital records (33 with current use and 60 with no current use). Most exclusions were of patients with neoplasm, cholelithiasis, and serologically confirmed viral hepatitis. A total of 34 validated cases met all the study criteria, 16 of whom were current users of non-steroidal anti-inflammatory drugs (table II).

The mean age of the cases in the group currently using the drugs was 66 (range 22-93) years and in the group not currently using the drug 60 (21-90) years. The onset of the liver injury (first symptoms noticed) began within 10 days before admission in $24(71 \%)$ of the cases. One patient developed symptoms more than one month before admission. Two of the 34 patients 
admitted to hospital died. Table III presents the clinical signs and symptoms leading to admission. The indication for use of non-steroidal anti-inflammatory drugs was available for 12 patients, and in all these cases osteoarthritis was the underlying diagnosis. Table IV shows details of other hepatotoxic drugs taken before admission.

TABLE III-Details of clinical presentation in patients with acute liver injury according to use of non-steroidal anti-inflammatory drugs. Figures are numbers of patients

\begin{tabular}{lcc}
\hline Signs and symptoms & $\begin{array}{c}\text { Current use } \\
(\mathrm{n}=16)\end{array}$ & $\begin{array}{c}\text { No current use } \\
(\mathrm{n}=18)\end{array}$ \\
\hline Jaundice & 7 & 10 \\
Malaise & 5 & 3 \\
Abdominal pain & 1 & 4 \\
Nausea and vomiting & 2 & 0 \\
Systemic reaction & $1^{\star}$ & $1 \dagger$ \\
\hline
\end{tabular}

* Rash, anorexia, nausea, and jaundice (cephalexin comedication)

tAbdominal pain, rash, vomiting, fever, and jaundice (erythromycin comedication)

TABLE IV-Numbers of patients who took other hepatotoxic drugs in 60 days before admission to hospital ${ }^{12}$ with acute liver injury according to use of non-steroidal anti-inflammatory drugs

\begin{tabular}{lcc}
\hline & $\begin{array}{c}\text { Current use } \\
(\mathrm{n}=10)^{\star} \dagger\end{array}$ & $\begin{array}{c}\text { No current use } \\
(\mathrm{n}=14)^{\star} \ddagger\end{array}$ \\
\hline Allopurinol & 1 & 1 \\
Captopril & 1 & 0 \\
Carbamazepine & 0 & 1 \\
Cephalexin & 1 & 0 \\
Cimetidine & 1 & 3 \\
Erythromycin & 1 & 2 \\
Oestrogens & 2 & 0 \\
Halothane & 0 & 2 \\
Isoniazid/para-aminosalicylic acid & 1 & 0 \\
Levodopa & 1 & 0 \\
Methyldopa & 0 & 2 \\
Nitrofurantoin & 0 & 1 \\
Penicillamine & 0 & 1 \\
Phenobarbitone & 0 & 1 \\
Dextropropoxiphene & 0 & 1 \\
Co-trimoxazol & 3 & 2 \\
Tolbutamide & 1 & 0 \\
\hline
\end{tabular}

* Some patients took more than one drug.

†Drugs other than non-steroidal anti-inflammatory drugs clinically suspected partially to cause liver injury in seven cases.

$\ddagger$ Drugs other than non-steroidal anti-inflammatory drugs clinically suspected partially to cause liver injury in nine cases.

The length of admission ranged from one to 34 days with 17 patients staying less than one week and seven patients staying two weeks or more. Of the six cases occurring among patients currently using nonsteroidal anti-inflammatory drugs with no concomitant use of other hepatotoxic drugs, only one had use of non-steroidal anti-inflammatory drugs as a cause of the liver injury recorded on the discharge summary. Of the 24 admissions when the patient had taken at least one other hepatotoxic drug, these drugs were thought by the treating physicians to account partially for the acute liver injury in 16 cases. The daily doses used were in line with the average recommended for the different non-steroidal anti-inflammatory drugs. There were 10 cholestatic liver injuries out of 16 in the group taking non-steroidal anti-inflammatory drugs compared with six out of 18 in the group not taking these drugs.

The crude rate ratio (95\% confidence interval) associated with use of non-steroidal anti-inflammatory drugs was $2 \cdot 3(1 \cdot 1$ to $4 \cdot 9)$. The figure for men was $3 \cdot 1$ $(1.0$ to $9 \cdot 6)$ and for women $2 \cdot 0(0 \cdot 8$ to 4.5$)$. There was no interaction between use and age, but the incidence of admission to hospital for acute liver disorders among people aged over 65 years was three times that among younger people (data not shown). The rate ratio adjusted for age and sex was $1.7(0.8$ to $3 \cdot 7)$. Redefinition of current use of non-steroidal anti-inflammatory drugs as up to 90 days after the prescription did not materially change the rate ratio estimate, which was 2.5 $(1.3$ to 4.9$)$. When the cases were restricted to those with no concomitant use of hepatotoxic drugs other than non-steroidal anti-inflammatory drugs the rate ratio was $4.0(0.9$ to 19.0$)$ with the overall denominator being current use and no current use of non-steroidal anti-inflammatory drugs in person time.

Table $\mathrm{V}$ presents the risk associated with duration of exposure to non-steroidal anti-inflammatory drugs. The rate ratio for people receiving only one prescription was $3.2(0.9$ to 9.0$)$, which was similar to that for those receiving from two to nine consecutive prescriptions. There was no increased risk for long duration, defined as 10 or more consecutive prescriptions.

TABLE $\mathrm{v}$-Incidence and rate ratio by duration of exposure to nonsteroidal anti-inflammatory drugs for 34 cases of acute liver injury

\begin{tabular}{lcccc}
\hline $\begin{array}{l}\text { Use of } \\
\text { non-steroidal } \\
\text { anti-inflammatory } \\
\text { drugs* }\end{array}$ & $\begin{array}{c}\text { Person } \\
\text { years }\end{array}$ & $\begin{array}{c}\text { No of } \\
\text { cases }\end{array}$ & $\begin{array}{c}\text { Incidence } \\
\text { rate } \\
\text { (100000 } \\
\text { person years) }\end{array}$ & $\begin{array}{c}\text { Rate ratio }(95 \% \\
\text { confidence } \\
\text { interval) }\end{array}$ \\
\hline 0 & 467906 & 18 & 4 & 1 \\
Any use & 177550 & 16 & 9 & $2 \cdot 3(1 \cdot 1$ to $4 \cdot 9)$ \\
1 & 40149 & 5 & 12 & $3 \cdot 2(0 \cdot 9$ to $9 \cdot 0)$ \\
$2-4$ & 38041 & 5 & 13 & $3 \cdot 4(1 \cdot 0$ to $9 \cdot 5)$ \\
$5-9$ & 23006 & 3 & 13 & $3 \cdot 4(0 \cdot 7$ to $11 \cdot 6)$ \\
$\geqslant 10$ & 76354 & 3 & 4 & $1 \cdot 0(0 \cdot 2$ to $3 \cdot 5)$
\end{tabular}

${ }^{\star}$ Categorised according to number of consecutive prescriptions.

\section{Discussion}

In this large, population based cohort study we $\stackrel{\circ}{د}$ found that subjects had twice the risk of newly $\overrightarrow{0}$ diagnosed acute liver injury when they were taking $O$ non-steroidal anti-inflammatory drugs as when they were not taking these drugs. Sixteen cases of acute liver $\frac{0}{0}$ injury required hospital admission during the 177550 person years of observation in the period immediately $\vec{\bullet}$ after prescriptions and 18 cases in the 467906 person ? years when non-steroidal anti-inflammatory drugs had 0 not been recently prescribed. The incidence in people currently using non-steroidal anti-inflammatory drugs was nine (6 to 15) cases per 100000 person years. The excess risk associated with current use was five $\mathbb{D}$ cases per 100000 person years. There was an increased risk in both men and women. The risk of admission to hospital was strongly related to age, but the rate ratio associated with current use was the same across age groups. There was some indication that the relative risk was greater early in the course of treatment. For subjects receiving 10 or more prescriptions the risk was essentially the same as when not taking non-steroidal anti-inflammatory drugs. None of the patients were taking a daily dose larger than the maximum recommended dose for the particular drug, but five were exposed to two different non-steroidal anti-응 inflammatory drugs in the 60 days before admission. $N$ The clinical signs and symptoms leading to admission $\rightarrow$ were alike in the two groups. There was a predominance of cholestatic liver injury among patients currently using non-steroidal anti-inflammatory drugs, whereas the principal type of liver injury when $\omega$ not using these drugs was hepatocellular.

The evaluation of the effect of non-steroidal antiinflammatory drugs on chronic liver disease is an important task in the overall assessment of benefit and + risk of these drugs but was beyond the scope of the present study. The main types of acute hepatic injuries are either cytotoxic (liver cell damage) or cholestatic $\frac{\rho}{0}$ (impairment of bile excretion). ${ }^{15}$ Biochemical tests of $\varrho$ the liver (alanine aminotransferase and aspartate aminotransferase) have been found to have inadequateô sensitivity and specificity to predict serious clinical liver injury. ${ }^{16}$ Most abnormal liver values found in theo general population exposed to non-steroidal anti- $\stackrel{?}{\rightleftharpoons}$ inflammatory drugs are transient and not followed by any serious liver injury. ${ }^{17}$ Also, this study shares the limitations of any research that uses only hospital based 
cases. All instances of self limiting liver injury not requiring admission would not have been detected. Severe liver disorders, on the other hand, may occur without early changes in standard liver function. ${ }^{18}$

Acute liver injury associated with use of nonsteroidal anti-inflammatory drugs is considered to be the result of current rather than past exposure. Therefore we chose as the comparison group the same people who had taken non-steroidal anti-inflammatory drugs at a time when they were no longer taking the drugs. ${ }^{19}$ We compared the incidence rate of acute liver injury during the total person time when subjects were taking non-steroidal anti-inflammatory drugs with the incidence rate during the total person time when they were not. The use of the exposed population as its own comparison group contributes to a reduction in confounding. Risk characteristics that do not change with time will necessarily be the same for exposed and nonexposed patients. We must, however, consider the possibility of changes in the use of non-steroidal antiinflammatory drugs when applying this kind of cross over study design. The decision to start or stop use may be influenced by the presence of prodromal symptoms of the acute liver injury. We could not directly assess the extent of bias related to the beginning of medication for early non-specific symptoms of liver injury not yet diagnosed. For the 12 current users, however, for whom information on the indication for use of nonsteroidal anti-inflammatory drugs was recorded, osteoarthritis was the underlying clinical condition. We evaluated the pattern of stopping treatment. Only four out of the 18 patients in the group not currently taking non-steroidal anti-inflammatory drugs had filled a prescription for non-steroidal anti-inflammatory drugs two to six months before admission to hospital; four had filled one prescription seven to 12 months before admission; and the remaining 10 had not filled a prescription in the year before admission. Increasing the criterion for current use of non-steroidal anti-inflammatory drugs to up to 90 days after the prescription did not materially change the rate ratio estimate.

The effects if non-steroidal anti-inflammatory drugs can be seen most clearly in a population free of the "background noise" of hepatotoxicity induced by other drugs. ${ }^{20}$ In the subpopulation with no use of other hepatotoxic drugs the rate ratio estimate of the effect of non-steroidal anti-inflammatory drugs on acute liver injury was larger than in the overall population.

Some of the patients did not undergo tests to rule out infectious hepatitis. In addition, diagnostic tests for hepatitis $C$ were not available during the study, and differential diagnosis for cholelithiasis was not always carefully considered. All these limitations must be considered when interpreting our results, and some cases may have been misclassified. Any misclassifica- tion, however, would be similar in the two groups and may therefore have resulted in some underestimation of the true relative risk. Given the low incidence of acute liver injury, the impact on the excess risk would have been small.

In summary, our results show that admissions to hospital for acute non-infectious liver injury are rare and that current use of non-steroidal anti-inflammatory drugs is associated with a twofold increase in the risk and an excess risk of five per 100000 person years.

We thank Edith Malcolm and the staff of the pharmacoepidemiology unit in Saskatchewan for their expert collaboration with the Saskatchewan health databases and the organisation of the medical record abstraction process and Drs David Henry (University of Newcastle), Hershel Jick (Boston University), and Bruno Stricker (Netherlands cente for monitoring of adverse reactions to drugs), who read earlie versions of the manuscript.

This study was supported by a grant from CIBA-GEIGY AG, Basel. It is based in part on data provided by the Saskatchewan department of health. The interpretation and conclusions contained herein do not necessarily represent those of the government of Saskatchewan or the Saskatchewan department of health

1 Lewis $\mathrm{JH}$. Hepatic toxicity of nonsteroidal anti-inflammatory drug. Clin Pharm 1984;3:128-38.

2 Beard K, Belic L, Aselton P, Perera D, Jick H. Outpatient drug-induce parenchymal liver disease requiring hospitalization. $f$ Clin Pharmacol 1986;26:633-7.

3 Jick H, Derby LE, Garcia Rodriguez LA, Jick SS, Dean AD. Liver disease associated with diclofenac, naproxen and piroxicam. Pharmacotherapy 1992;12:207-12.

4 Strand LM, West R. The health databases in Saskatchewan. In: Strom B, ed Pharmacoepidemiology. New York: Churchill Livingstone, 1989:189-200.

5 Garcia Rodriguez LA, Walker AM, Pérez Gutthann S. Non-steroidal antiinflammatory drugs and gastrointestinal hospitalizations in Saskatchewan a cohort study. Epidemiology 1992;3:337-42.

6 Sherlock S, ed. Diseases of the liver and biliary system. Oxford: Blackwell, 1981.

7 Biorneboe M, Iversen O, Olsen S. Infective hepatitis and toxic jaundice in a municipal hospital during a five-year period. Acta Med Scand 1967;182:491-
mune 501 .

8 Ross RM. Hepatic dysfunction secondary to heart failure. Am $\mathcal{f}$ Gastroenter 1981;76:511-8.

9 Raviolo P, Rizzetto M, Tabone M. Colestasi intraepatica in corso ipertiroidismo. Recenti Prog Med 1991;82:319-23.

10 Gomar Sancho C. Anestesia y alteraciones hepáticas postoperatorias. Med Clin 1988;90:579-82.

11 Report of an international consensus meeting. Criteria of drug-induced live disorders. I Hepatol 1990;11:272-6.

12 Stricker BH, Spoelstra P, eds. Drug-induced hepatic injury. Amsterdam: Elsevier, 1985

13 Walker AM, ed. Observation and inference: an introduction to the methods of epidemiology. Newton: Epidemiology Resources Inc, 1991.

14 Martin D, Austin $H$. An efficient program for computing condition maximum likelihood and exact confidence limits for a common odds ratio. Epidemiol 1991;2:359-62.

15 Pessayre D, Larrey D. Acute and chronic drug-induced hepatitis. Baillieres Clin Gastroenterol 1988;2:385-422.

16 Van Ness MM, Diehl AM. Is liver biopsy useful in the evaluation of patient with chronically elevated liver enzymes? Ann Intern Med 1989;111:473-8.

17 Zimmerman HJ. Effects of aspirin and acetaminophen on the liver. Arch Inter Med 1981;141:333-42.

18 Davis M. Drugs and abnormal liver function tests. Adv Drug Reac Bul 1989;139:520-3

19 Ray WA, Griffin MR. Use of medicaid data for pharmacoepidemiology. Am f Epidemiol 1989;129:837-49.

20 Rothman $\mathrm{KJ}$, Poole $\mathrm{C}$ A strengthening programme for weak associations. Int F Epidemiol 1988;17:955-9.

(Accepted 30 fuly 1992)

\section{Generalised pustular psoriasis: response to topical calcipotriol}

\section{J Berth-Jones, J Bourke, K Bailey, R A C Graham-Brown, P E Hutchinson}

Pustular psoriasis is a life threatening disease ${ }^{1}$ and usually requires treatment with systemic drugs which themselves carry significant risks. Calcipotriol, a vitamin $\mathrm{D}$ analogue, is an effective new topical treatment for psoriasis vulgaris. ${ }^{2}$ This is the first report of its use in pustular psoriasis.

\section{Case reports}

Three consecutive patients admitted with pustula psoriasis were treated with calcipotriol ointment 50 $\mu \mathrm{g} / \mathrm{g}$ (Dovonex).

Case 1-A 68 year old woman had been controlling her psoriasis using tar and betamethasone valerate ointment until three weeks before admission. Her skin then deteriorated until $45 \%$ of her body surface was affected by erythema and pustulation. Calcipotriol ointment was applied twice daily. Within 24 hours pustulation had completely resolved. She continued to improve and was discharged after three weeks to continue using the same treatment. In total, $300 \mathrm{~g}$ calcipotriol ointment was applied during the admission.
Correspondence to: 